IZA DP No. 5249

Are Microloans Bad for Growth?

Patrick M. Emerson

Bruce McGough

October 2010

Forschungsinstitut zur Zukunft der Arbeit Institute for the Study of Labor 


\title{
Are Microloans Bad for Growth?
}

\author{
Patrick M. Emerson \\ Oregon State University \\ and IZA \\ Bruce McGough \\ Oregon State University
}

\section{Discussion Paper No. 5249 \\ October 2010}

\author{
IZA \\ P.O. Box 7240 \\ 53072 Bonn \\ Germany \\ Phone: +49-228-3894-0 \\ Fax: +49-228-3894-180 \\ E-mail: iza@iza.org
}

\begin{abstract}
Any opinions expressed here are those of the author(s) and not those of IZA. Research published in this series may include views on policy, but the institute itself takes no institutional policy positions.

The Institute for the Study of Labor (IZA) in Bonn is a local and virtual international research center and a place of communication between science, politics and business. IZA is an independent nonprofit organization supported by Deutsche Post Foundation. The center is associated with the University of Bonn and offers a stimulating research environment through its international network, workshops and conferences, data service, project support, research visits and doctoral program. IZA engages in (i) original and internationally competitive research in all fields of labor economics, (ii) development of policy concepts, and (iii) dissemination of research results and concepts to the interested public.
\end{abstract}

IZA Discussion Papers often represent preliminary work and are circulated to encourage discussion. Citation of such a paper should account for its provisional character. A revised version may be available directly from the author. 
IZA Discussion Paper No. 5249

October 2010

\section{ABSTRACT}

\section{Are Microloans Bad for Growth?}

This paper constructs a two-period overlapping generations model of human capital investment decisions where a microloan program designed to finance entrepreneurial activities is active. It is shown that, in the presence of human capital externalities (social returns to education) there exists a range of microloan amounts that are growth depressing and welfare decreasing through their affect on the opportunity cost of schooling. By increasing the opportunity cost of schooling, microloans divert investment away from human capital: by failing to internalize the social returns to education, households' individually optimal investment decisions in the face of microcredit availability act to depress the growth of the economy and result in sub-optimal welfare outcomes.

JEL Classification: E24, O10, O40

Keywords: microloans, growth, human capital

Corresponding author:

Patrick M. Emerson

Department of Economics

Oregon State University

303 Ballard Hall

Corvallis, Oregon 97331

USA

E-mail: patrick.emerson@oregonstate.edu 


\section{Introduction}

Microfinance and microloans have become one of the most celebrated development success stories of the last quarter century. Microfinance institutions have proliferated in the developing world and have become increasingly popular in developed countries. Praised for their ability to successfully provide access to credit to a population that had previously been shut out of formal credit markets, these organizations have traditionally described their activities as representing a successful poverty alleviation strategy. Empirical evidence that such claims are true has been elusive with many studies failing to convincingly isolate a causal link and find evidence that the programs positively influence various measures of welfare such as household consumption. Studies of the effects of microloans also tend to focus on short-term outcomes, neglecting the long-term implications of the programs.

Most existing studies of the effect of microloans on welfare focus on measures of household consumption. There are a few studies, however, that examine other household investments such as those in the education of children. These studies focus on the short term educational consequences of microloans, and have also found conflicting evidence about the effect of microloans on educational investments. Two recent studies, however, have found no or even negative effects of microloan receipt on investments in the education of the children in the household.

It is, perhaps, hard to understand how microloans - especially those that 
inject outside capital into an essentially closed economy - could actually be welfare reducing. In a static setting, the introduction of microloans represents an expansion of the choice set, which should result in increased utility. This perception has contributed to their status as perhaps the leading anti-poverty agenda in low income countries.

However, in this paper we show that the nature of these loans, which are typically small with quick commencement of repayment, can be quite antithetical to long-term investment in human capital. ${ }^{1}$ If households have binding time constraints then microloans can raise the current opportunity cost of schooling, causing households to concentrate more on entrepreneurial activities and less on education. This can have a beneficial short-term welfare effect for households but a detrimental long-term effect for the household dynasty. By raising the opportunity cost of schooling and demanding a quick return on investment, microloans might actually serve to suppress human capital accumulation in the communities in which they are introduced. In a world in which there are social returns to education, the long-term effect of microloans might actually be, therefore, to impede economic growth rather than help it. This, in turn, can lead to decreased welfare. In the end, by acting to suppress growth, microloan programs can result in increased rather than decreased poverty.

This paper constructs a two-period overlapping generations model of

\footnotetext{
${ }^{1}$ See Morduch (1999) for a good overview of the economics of peer lending and characteristics of typical microfinance programs.
} 
household investment decisions where a microloan program designed to finance entrepreneurial activities exists. The model shows that the effect on educational outcomes of recipient households will depend on both the impact of easing the resource constraint on educational investment and the raising of the opportunity cost of education. These two forces are in tension and the resolution of this tension has major implications for growth. The paper then describes conditions in which microloans can lead to lower growth and lower welfare through their depressing effect on human capital investments.

In the end, it is shown that despite the fact that microloans introduce new resources into an economy, they can be detrimental to economic growth. The paper goes on to discuss some particular aspects of microloans that could contribute to the adverse consequences of the loan program, in particular the size and repayment schedule of the loans.

\section{Related Literature}

Microfinance as a development tool and policy has spread rapidly throughout the world. The Microcredit Summit Campaign estimates that in 2007, microcredit had reached almost 155 million recipients, almost 110 million of whom were women and over 106 million were considered to be among the world's poorest (Daley-Harris, 2009). Despite the popularity and spread of microcredit, relatively little is known about the effect of credit receipt on the outcomes of individuals and households. Because of this lacuna, there are 
many recent and ongoing studies of the effects of the distribution of microcredit to the poor.

The early economic literature on microfinance focused on group liability as a way to overcome the lack of information and collateral in low-income country credit markets (Stiglitz 1990, Ghatak and Guinnane 1999, Armendariz de Aghion and Morduch 2005). Group lending was shown to have the potential to overcome these information and collateral problems. With shared liability, the entire group becomes responsible for repayment and thus group members have an incentive monitor each other. And indeed the evidence suggests that group lending and peer-monitoring have been very effective: repayment rates for microloans average over 90 percent (Grameen Foundation).

Empirical studies of the effects of microloans on the outcomes of the participants are numerous and often conflicting. Pitt and Khandker (1998) find large positive consumption effects from Grameen Bank loans, especially for women. Coleman (1999), however, finds little to no impact of a microcredit program in Northeast Thailand on recipient welfare, but notes that failure to control for selection would lead to a conclusion of positive impacts. Kaboski and Townsend (2005) using a natural experiment approach find positive consumption impacts of microloans, but not on investment. Karlan and Zinman (2009) use randomization of marginal clients to evaluate the impact of consumer lending in South Africa, and find that the receipt of microcredit improves the welfare of the recipients. In a novel approach to address 
the selection problem, Schroeder (2010) examines consumption effects from Grameen Bank lending in Bangladesh using an estimation strategy that relies on second-moment restrictions and finds positive and significant consumption effects from microloans.

To address the problem of selection, randomized designs have been used to explore the impact of microfinance product design such as group lending and repayment schedules (e.g. Giné and Karlan (2006, 2009), Field and Pande (2008)). Banerjee, et. al. (2009) is the only large-scale randomized experiment that examines outcomes from a microcredit intervention In this study, the authors find that durable consumption rises but non-durable consumption does not. More importantly for the current analysis, they do not find any measurable effects on health or educational investment.

Studies of the specific effects of microloans on educational investment and educational outcomes are few. The aforementioned Banerjee, et. al. (2009) study included a measure of educational investment and found no measurable effect. However, a study of the effect of microloan receipt in Bangladesh by Islam and Choe (2009) found that microloans reduced school enrollment among children of recipient households. Maldonadoa and González-Vega (2008) find evidence from Bolivia that microloans increase the labor demands of children and thus potentially lower educational investment. However, In a study of two districts in Buenos Aires, Becchetti and Conzo (2010) find positive effects of microloans on schooling.

The theoretical analysis relies critically on the presence of human capi- 
tal externalities. Such agglomeration externalities are empirically very well founded. Unlike the relative paucity of studies of microloans and education, many studies have found significant social returns to education (see, e.g. Psacharopoulos and Patrinos, 2002 for a good meta-analysis of the empirical literature on social returns to education).

The theoretical literature on microfinance has largely been confined to the aforemantioned studies of the efficacy of microcredit and peer lending in overcoming information and collateral constraints (e.g., Besley and Coate, 1995; Varian, 1989) and less focused on recipient households or how their choices affect an economy as in the present study. Perhaps the most closely related paper to the current study is Wydick (1999) who constructs a static model of household investment decisions and illustrates how access to microcredit for capital investments can increase the value of the marginal product of the labor of children in the household which raises the opportunity cost of education and thus depresses the level of educational investment. An empirical analysis using Guatemalan data reveals that when families use microcredit to finance capital investments the likelihood a child in the household will be withdrawn from school to work increases. The aforementioned paper by Maldonadoa and González-Vega (2008) also constructs a static model of household investment. The current study expands on these static models to examine the long-run consequences of microcredit on the growth of an economy and the welfare of its inhabitants. 


\section{Model and results}

The introduction of micro-loans into a developing economy provides liquidity access to productive agents who, because of financial market incompleteness, would otherwise be denied funding for their projects; and it is natural to think that this increase in market efficiency improves welfare. However, access to funds also raises the opportunity cost of education and thus may lower the aggregate level of human capital. Absent external benefits to education, the increase in financial market efficiency is necessarily welfare enhancing, and this result holds even with the potential reduction in aggregate human capital. On the other hand, if the economy exhibits agglomeration effects then the welfare implications of micro-loan availability are less clear.

To assess whether and when micro-loans may reduce aggregate human capital and welfare, we develop a simple overlapping generations model of competing interests. Young agents must choose effort levels directed toward education or entrepreneurial production as made available via micro-loans. Old agents have access to micro-loans, but may also produce via a technology dependent on both individual and aggregate human capital. By stripping the model of features incidental to the trade-off between human capital accumulation and goods production, we are then able to obtain sharp results characterizing the potential for welfare reduction.

We consider a two-period model with agglomeration effects and no population growth. For simplicity, both young and old own their production 
technology and consume what they produce. This yeoman farmer assumption is a technical device which helps expose the salient features of the model; however, we could equally develop the arguments by assuming competitive goods and labor markets, and inelastic labor supply.

\subsection{Equilibrium in the general model}

We begin with a fairly general specification; this helps us identify tangential aspects of the model that may be simplified to provide sharpness while imparting little cost to robustness. A young agent has unit time endowment which he may divide between goods production and human capital accumulation. Goods are produced via a primitive technology $f$ which takes only labor as a input; but, we also assume that micro-loans enhance labor productivity. Letting $c_{1 t}$ be goods consumption of the representative young agent in time $t$, we write

$$
\begin{aligned}
c_{1 t} & =f\left(M_{t}, n_{1 t}\right)-\left(1+i_{t}\right) M_{t} \\
h_{t} & =g\left(1-n_{1 t}\right) .
\end{aligned}
$$

Here $n$ is the labor supplied by the agent towards good production, $i$ is the interest rate on the loan $M$ (for simplicity, we assume repayment is made contemporaneously), $h$ is the attained level of human capital accumulation, 
and $g$ captures the production of human capital accumulation. ${ }^{2}$

An old agent also has a unit of time which he supplies inelastically to goods production. He has access to the same technology as when young, but also to an additional technology, $F$. Letting $c_{2 t}$ be goods consumption of the representative agent who is old in period $t$, we write

$$
c_{2 t+1}=F\left(h_{t}, H_{t+1}, 1-n_{2 t+1}\right)+f\left(M_{t+1}, n_{2 t+1}\right)-\left(1+i_{t+1}\right) M_{t+1} .
$$

Here $F$ captures the education enhanced production technology available to the old. Notice that this technology depends on both the individual human capital acquired when young, $h_{t}$, and the time $t+1$ level of aggregate human capital $H_{t+1}$.

Young agents in time $t$ receive utility, $u$, from consumption in periods $t$ and $t+1$, as well as from the well-being of their progeny; they make time $t$ decisions to maximize expected utility subject to the constraints indicated above and conditional on available information. Let $I_{t}$ be the collection of all variables dated $t-n$ for $n \geq 0$. Let $V_{t}\left(I_{t-1}\right)$ be the value function for the representative young agent time $t$. Then $V_{t}\left(I_{t}\right)$ is obtained by choosing $c_{1 t}, n_{t}, h_{t}, c_{t+1}$ to maximize

$$
u\left(c_{1 t}, c_{2 t+1}, V_{t+1}\left(I_{t+1}\right)\right)
$$

\footnotetext{
${ }^{2}$ Implicit in our production formulation is that the young agent supply labor inelastically: no value is place on leisure.
} 
subject to the constraints $(1)-(3)$.

Because there is no uncertainty in the economy - no stochastic component to the model - we focus on perfect foresight behavior and exclude an expectations operator in the young agent's problem. Equilibrium in the model is obtained by exploiting the assumption that all agents are identical, and identifying individual and aggregate human capital: $H_{t+1}=h_{t}$. Thus an equilibrium is any collection of sequences $\left\{c_{1 t}, c_{2 t}, h_{t}, n_{1 t}, n_{2 t}, H_{t}\right\}$ satisfying $H_{t+1}=h_{t}$, constraints $(1)-(3)$, and the representative agent's first order conditions.

\subsection{Equilibrium in the stylized model}

The level of generality sustained in the previous subsection is useful for defining the modeling environment and understanding the broadest set of natural assumptions; however, to make progress and provide sharp conclusions, further assumptions are required. We retain the potential for agglomeration effects, thereby placing a wedge between individual and social opportunity costs, and we abstract from other production non-linearities. The utility specification is modified to eliminate dependence on progeny, and to impose inter-temporal additivity and that instantaneous felicity exhibits constant relative risk aversion; and we abstract from the need for loan repayment. ${ }^{3}$ Finally, the education enhanced production technology $F$ is taken to be "all

\footnotetext{
${ }^{3}$ Alternatively, we may assume that the primitive technology is written in "net of repayment" terms.
} 
or nothing" in labor: using $F$ is a full-time job. This modeling feature is incorporated using an indicator function $\delta(n)$ which is equal to unity when $n=1$ and zero otherwise, together with the assumption that $F(h, H, 0)=0$. These simplifications lead to the following representative agent's problem:

$$
\begin{aligned}
\max & \frac{1}{1-\sigma}\left(c_{1 t}^{1-\sigma}+c_{2 t+1}^{1-\sigma}-2\right) \\
& c_{1 t}=m_{t}\left(M_{t}\right) n_{1 t} \\
& h_{t}=1-n_{1 t} \\
& c_{2 t+1}=F\left(h_{t}, H_{t+1}, \delta\left(1-n_{2 t+1}\right)\right)+m_{t+1}\left(M_{t+1}\right) n_{2 t+1}
\end{aligned}
$$

Here $m_{t}\left(M_{t}\right)$ is the productivity of primitive labor as dependent on the level of micro-loans. In the sequel, we simply take $m_{t}$ be the the time $t$ level of micro-loans.

Corner solutions are possible in this model, but given the utility specification, they may be disregarded by appropriate choice of the production function $F$; therefore, we focus on interior behavior. Note, in particular, that for appropriately scaled $F$, older agents will never choose to acquire micro loans; thus abusing notation slightly, we may simplify (5) to be

$$
c_{2 t+1}=F\left(h_{t}, H_{t+1}\right) .
$$

The lack of lags in the production technologies allows us to abstract from time-dependent equilibrium when writing the first order conditions and equi- 
librium restrictions. The agents' FOC is given by

$$
\left(\frac{c_{2}}{c_{1}}\right)^{\sigma}=\frac{F_{h}(h, H, n)}{m}
$$

Imposing the equilibrium restriction that $h=H$ yields the following equation identifying equilibrium in the stylized model:

$$
F(H, H)^{\sigma} m^{1-\sigma}=F_{h}(H, H)(1-H)^{\sigma} .
$$

Denote by $H^{s s}$ a solution to this model. Then equation (7) may be analyzed to assess the impact on $H^{s s}$ of exogenous changes in $m$.

\subsection{Comparative Statics}

Our intuition is that the availability of micro-loans raises the opportunity cost of education and subsequently decreases equilibrium aggregate human capital. Whether this decrease obtains depends delicately on income/substitution effects, as captured by the elasticity $\sigma$, as well as the agglomeration impact of $H$ on individual human capital productivity. To assess these dependencies, $\partial H^{s s} / \partial m$ may be computed explicitly. The resulting expression is complicated and of little intuitive value, but concise results are available.

Proposition 1 If $\sigma<1$ then there exists $\Delta>0$ so that $F_{h h}+F_{h H}<\Delta$ implies $\partial H^{s s} / \partial m<0$. 
The proof of this proposition, as well as an explicit formula for $\partial H^{s s} / \partial m$, is provided in the Appendix.

To interpret this proposition, note that the value of $m$ in part measures the price of consumption today in terms of consumption tomorrow: if $m$ increases then the price goes down. When $\sigma<1$, the substitution effect dominates the income effect so that agents have a tendency to choose consumption today at the expense of education today and consumption tomorrow. However, the price of $c_{1}$ in terms of $c_{2}$ is also affected by $F_{h}$, which is why the second condition, $F_{h h}+F_{h H}<\Delta$, plays a role. As $F_{h}$ increases, the price of $c_{1}$ in terms of $c_{2}$ rises, thus providing agents an incentive to attain more education today, in favor of consumption tomorrow. The condition $F_{h h}+F_{h H}<\Delta$ restricts the increase in $F_{h}$ given an increase in $H$ so that, in equilibrium, the influence of $F_{h}$ on relative price is smaller than the influence of $m .^{4}$

Proposition 1 confirms our intuition, and provides the main result of the paper: by raising the opportunity cost of education, micro-loans may reduce the aggregate level of human capital. Human capital accumulation is widely held as an important determinant of long run economic growth and a key to escaping poverty traps; through this lens, we may broadly interpret Proposition 1 as indicating that, and providing conditions under which, micro-loans may be welfare reducing. The simple structure of our

\footnotetext{
${ }^{4}$ In general, $F_{h h}<0$ and $F_{h H}>0$, so the condition could be similarly stated that $F_{h H}$ not be too large. The precise condition bounding $F_{h H}$ is given in the Appendix, and may not be at all restrictive.
} 
model allows us to strengthen this point via direct computation. Denote by $c_{i}^{s s}$ steady-state consumption, and set

$$
\begin{aligned}
W(m) & =\frac{1}{1-\sigma}\left(\left(c_{1}^{s s}\right)^{1-\sigma}+\left(c_{2}^{s s}\right)^{1-\sigma}-2\right) \\
Y(m) & =c_{1}^{s s}+c_{2}^{s s}
\end{aligned}
$$

where we interpret $W$ as welfare and $Y$ as output (gdp). We have the following result:

Proposition 2 Suppose $\sigma<1$.

1. $\partial W / \partial m<0$ if and only if

$$
\frac{\partial H^{s s}}{\partial m}<-\frac{F_{h}(1-H)}{m F_{H}}
$$

2. $\partial Y / \partial m<0$ if and only if

$$
\frac{\partial H^{s s}}{\partial m}<\left\{\begin{array}{lll}
\frac{-(1-H)}{F_{h}+F_{H}-m} & \text { if } & F_{h}+F_{H}-m>0 \\
\frac{(1-H)}{F_{h}+F_{H}-m} & \text { if } & F_{h}+F_{H}-m<0
\end{array}\right.
$$

The proof of this proposition is provided in the Appendix.

Proposition 2 provides precise conditions under which increasing access to micro-loans not only reduces aggregate human capital, but explicitly reduces welfare and economic output as well. The potential for welfare or gdp reduction given an increase in $m$ is somewhat surprising as, given our model- 
ing technique, increasing $m$ directly increases the productivity of the young while having no exogenous impact on the productivity of the old. These results turn on the presence of the agglomeration effect, as can be seen in condition (8): if $F_{H}=0$, this condition can not be satisfied. Of course, that the possibility of welfare reduction requires $F_{H}>0$ is not surprising: without agglomeration effects, an increase in $m$ simply enlarges the choice set of an individual, and thus can not be welfare reducing.

\subsection{An example}

The results in Propositions 1 and 2, which characterize some of the equilibrium comparative statics in our model, are contingent upon the assumption of equilibrium existence. This contingency could be eliminated by imposing restrictions on the production function $F$ guaranteeing that (7) has a solution in the interval $(0,1)$. Instead, we explore the potential for a well-understood functional form to yield the desired results. Let $F(h, H)=A h^{\alpha} H^{\beta}$ : here $A$ is a scaling parameter, which may be interpreted as total factor productivity, and $\alpha$ and $\beta$ are the elasticities of individual and aggregate human capital, respectively. With this specification for $F$, it can be shown that when $\sigma>1$, the equilibrium condition (7) always has a unique solution, and when $\sigma<1$ then uniqueness is guaranteed by the condition $\alpha+\beta<\frac{1}{1-\sigma}$, which is an assumption we maintain.

Figure 1 captures the implications of Propositions 1 and 2. For this and 


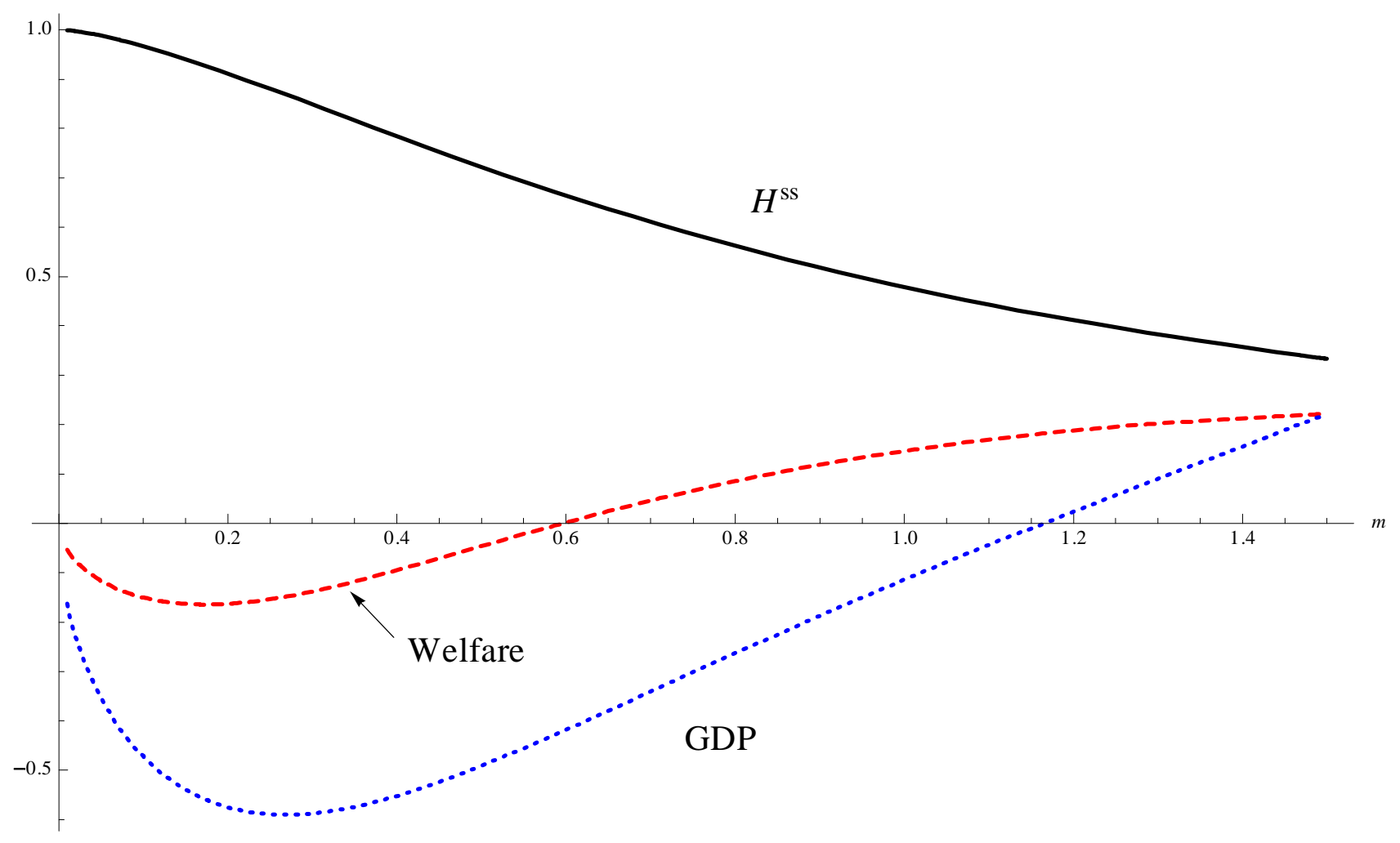

Figure 1: Equilibrium effects 
all figures below, we have chosen the parameter values $A=3$ and $\alpha=\beta=.5$, and we allow $m$ to vary between zero and 1.5; and in Figure 1, risk aversion is set to $\sigma=.4$. The solid curve plots the steady-state values of aggregate human capital for varying micro-loan levels. Notice that, consistent with Proposition 1 (and that $\sigma<1$ ), the curve is downward-sloping, indicating that increased $m$ leads to decreased aggregate investment in human capital.

Now consider the coarsely dashed curved, labeled "Welfare." For each $m$, the height of this curve measures the sum

$$
\frac{F_{h}(1-H)}{m F_{H}}+\frac{\partial H^{s s}}{\partial m}
$$

thus, by Proposition 2, when the curve is below the horizontal axis, $\partial W / \partial m<$ 0 . For the given specification of the model, if $m<\approx .6$, then, even though increasing $m$ raises the productivity capacity of the young, it lowers aggregate human capital enough to reduce welfare. A analogous, and even more robust deleterious impact on output is revealed via the finely dashed curve labeled "GDP" in Figure 1. This curve plots the sum

$$
\frac{(1-H)}{F_{h}+F_{H}-m}+\frac{\partial H^{s s}}{\partial m}
$$

and we checked that $F_{h}+F_{H}-m>0$; thus, by Proposition 2, when this curve is below the horizontal axis, $\partial Y / \partial m<0$. We find that for $m<\approx .1 .2$, the fall in $H$ associated to a rise in $m$ reduces economic output. 


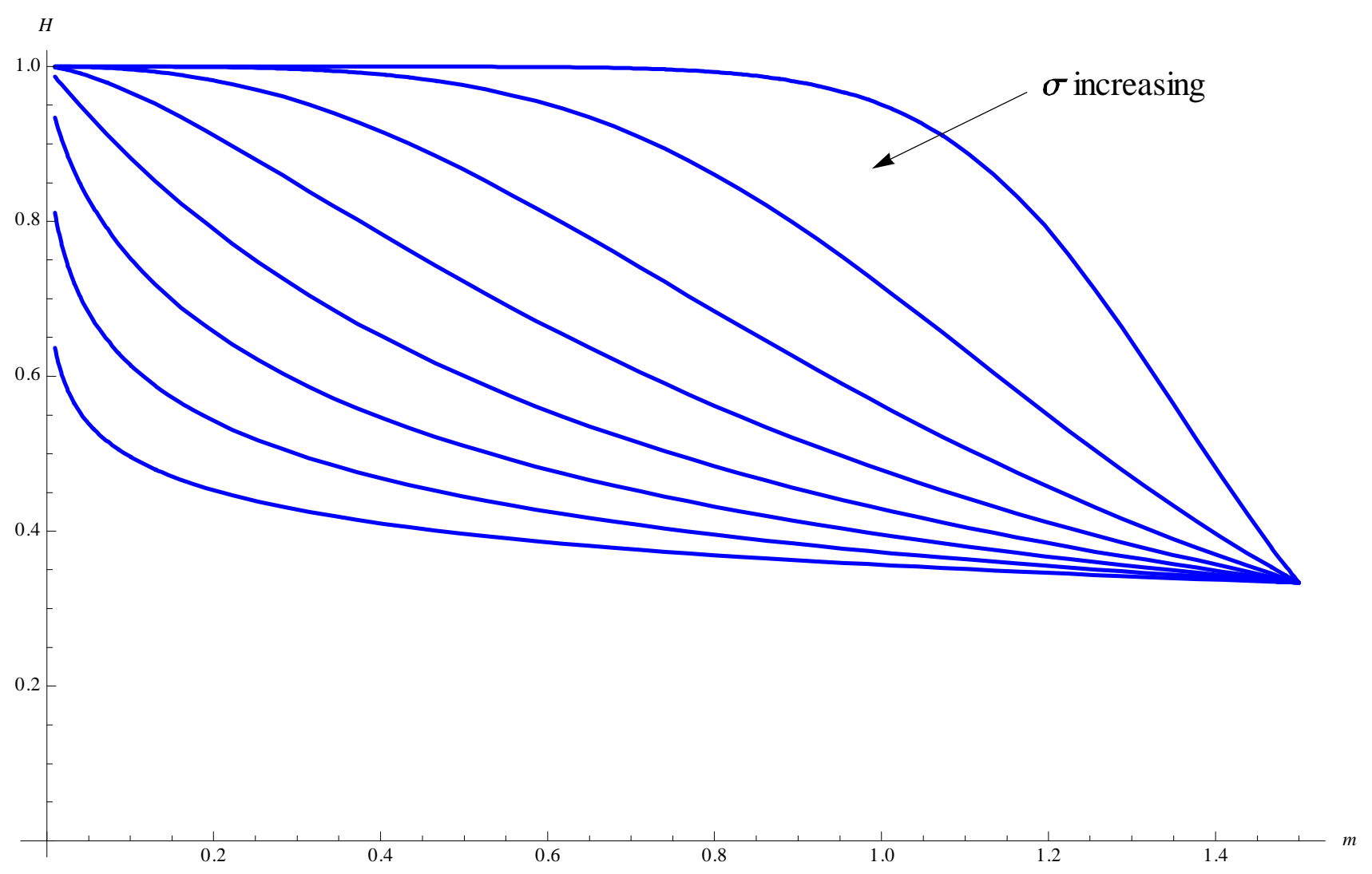

Figure 2: Steady-state 
Because of the importance of the income/substitution effect, we also present numerical analysis focusing on variation in $\sigma$. Figure 2 plots the steady-state values of aggregate human capital. Here, $\sigma$ increases from .1 to .8. The arrow in the figure indicates the way in which the plots of $H^{s s}(m)$ change as $\sigma$ increases. Note that for all plots, $H^{s s}$ is (at least weakly) decreasing in $m .^{5}$ For small $\sigma$ and small $m$, consumption in period one is very low as agents substitute heavily toward education and consumption in period 2. As $m$ increases, the relative price of consumption today falls and agents shift effort toward current period production.

The curves analogous to the Welfare curve in Figure 1 are plotted in Figure 3 for $\sigma \in\{.2, .4, .6, .8\}$. For small $\sigma$ micro-loans are always welfare reducing; for $\sigma=.4$, larger loans increase welfare; and for $\sigma=.6$ and .8 , increasing $m$ increases welfare: when the intertemporal elasticity of substitution is high (small $\sigma$ ) and $m$ rises thereby reducing the relative price of $c_{1}$, agents shift consumption to the first period and reduce investment in human capital, which, through the agglomeration channel, reduces production enough in the second period to reduce welfare; when $\sigma$ is larger, the substitution toward first period consumption is mitigated thereby reducing the deleterious effect of decreased human capital on period two production.

The same intuition holds for Figure 4, which plots the GDP curves cor-

\footnotetext{
${ }^{5}$ For small $\sigma$ and low values of $m$, Figure ?? appears to indicate that $H^{s s}=1$ and is independent of $m$; however, close inspection reveals that $H^{s s}<1$ and decreasing in $m$ for all curves plotted.
} 


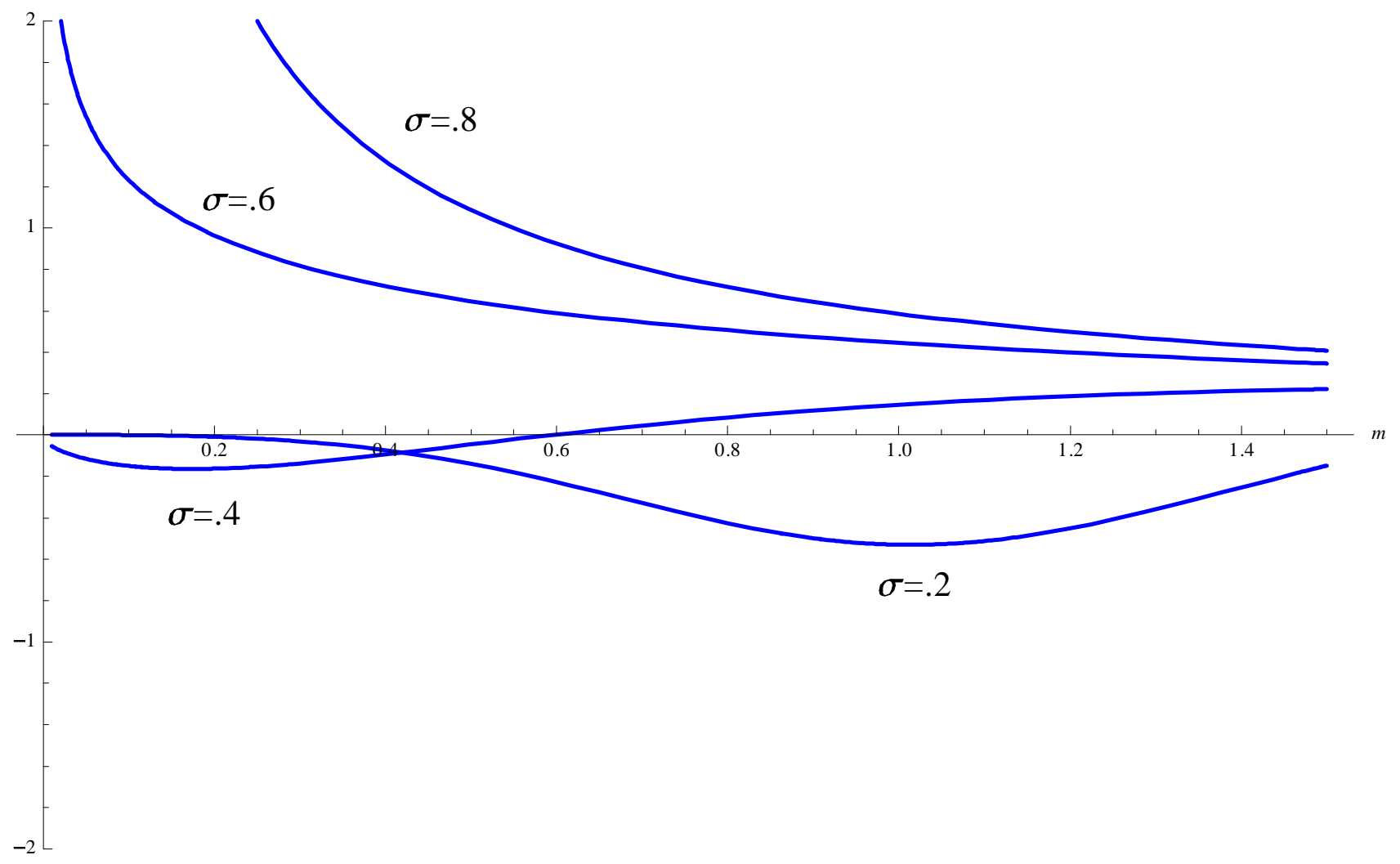

Figure 3: Welfare 


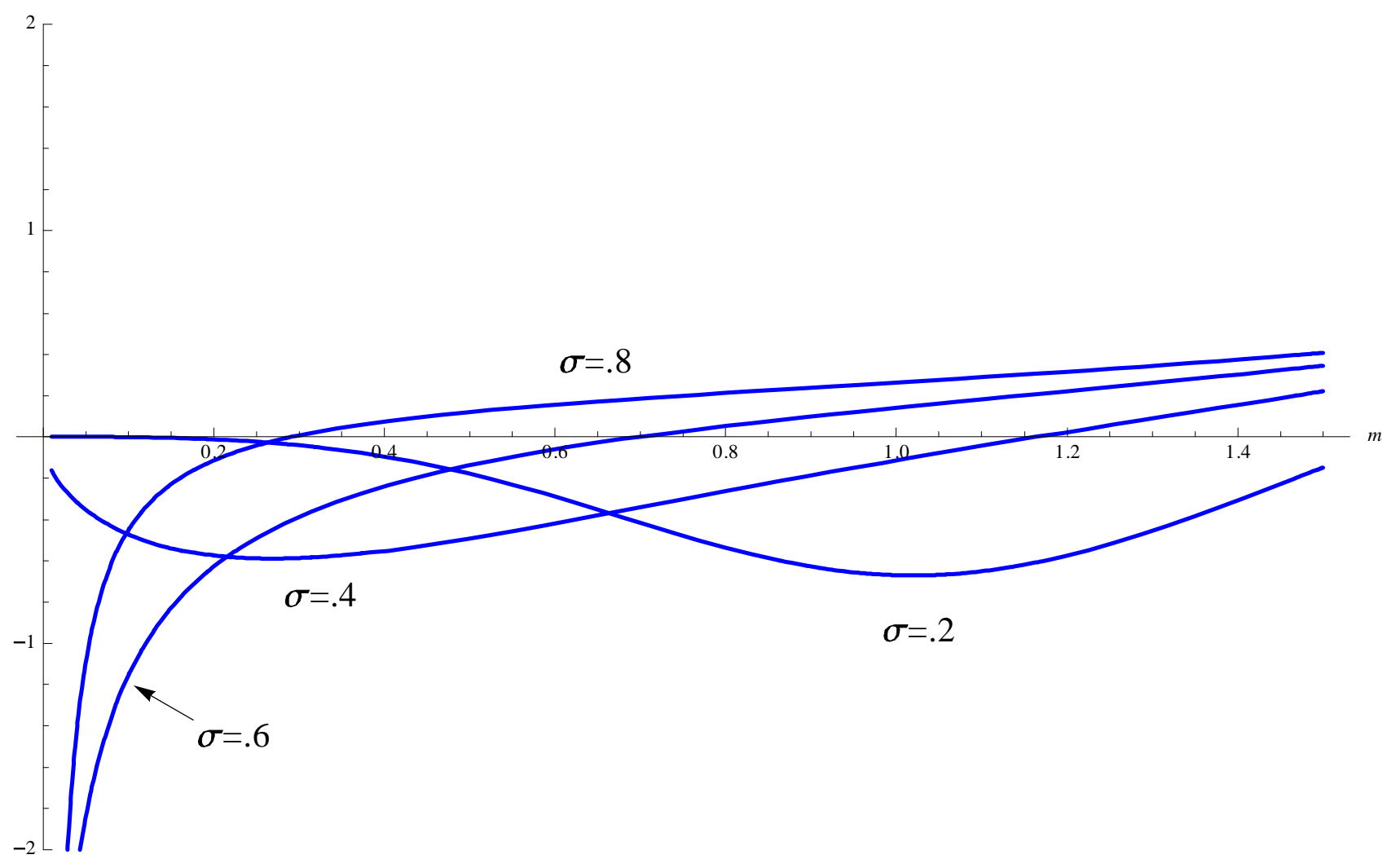

Figure 4: Output 
responding to $\sigma \in\{.2, .4, .6, .8\}$. Notice that even for large $\sigma$, small values of $m$ correspond to $\partial Y / \partial m<0$.

\section{Conclusion and Discussion}

Access to credit is scarce for poor families in developing countries. Microcredit institutions that provide credit to these households through peer-lending and other financial innovations provide liquidity that can have many positive attributes: investment in productive assets, insurance against income shocks and so on. But the nature of the typical microloan - that it is small and repayment begins very soon after the loan is acquired - may create incentives to make investments in very short-term productive assets at the expense of assets that pay off in the future. One such asset is human capital. Thus, microloans may actually increase the opportunity cost of education and reduce educational investment by recipient households. Such choices are individually rational. Education, however, has substantial social returns as well as private returns. Thus the decision by households that receive microloans to reduce investments in human capital ends up lowering societal productivity.

The sensitivity of the results in the paper to the assumed income and substitution effects may help expalin why previous empirical research has not reached consensus. It is quite likely that the same loan program applies in different contexts may have very different results in terms of education and other human capital investments. Blanket policy recommendations are thus 
inappropriate, but our model suggests two aspects of microloans that may contribute to constrained investment in education: the quick commencment of repayment and the size of the loan.

In the model presented in this paper, the return on investments is net of repayment, so in essence we are forcing immediate (within period) repayment. Relaxing this constraint would allow investments in assets that may have a higher present discounted values, but whose returns do not come until the next period. Student loans in the United States have the feature that repayment begins only when the investment begins to realize returns; when the recipient begins to work post-education. Such a loan program might be very beneficial to developing country economies as well.

It is also shown in the theory that larger loans can overcome the negative human capital aspects of microloans. It should be noted that this is despite the fact that microloans always depress human capital accumulation. Larger loans inject enough new capital into the economy that they overcome the damage done to the economy by the suppression of educational investments. Such new wealth might ease credit constraints of future generations, however, so the long term affect on growth and welfare might be positive. This is worth exporing in a fully dynamic model of microcredit on a similar stylized economy. 


\section{Appendix}

The proofs of Propositions 1 and 2 rely on comparative static analysis of the equilibrium condition

$$
F(H, H)^{\sigma} m^{1-\sigma}=F_{h}(H, H)(1-H)^{\sigma}
$$

Implicit differentiation yields

$$
\frac{\partial H^{s s}}{\partial m}=\frac{(\sigma-1) m^{-\sigma} F^{\sigma}}{\sigma m^{1-\sigma} F^{\sigma-1}\left(F_{h}+F_{H}\right)+\sigma F_{h}\left(1-H^{s s}\right)^{\sigma-1}-\left(1-H^{s s}\right)^{\sigma}\left(F_{h h}+F_{h H}\right)},
$$

where $F$ and all of its partials are evaluated at $\left(H^{s s}, H^{s s}\right)$. The proof of Proposition 1 follows from the observation that $\frac{\partial H^{s s}}{\partial m}<0$ provided that

$$
F_{h h}+F_{h H}<\Delta \equiv \frac{\sigma m^{1-\sigma} F^{\sigma-1}\left(F_{h}+F_{H}\right)+\sigma F_{h}\left(1-H^{s s}\right)^{\sigma-1}}{\left(1-H^{s s}\right)^{\sigma}}>0 .
$$

To prove Proposition 2, notice that

$$
W=\frac{1}{1-\sigma}\left(\left(c_{1}^{s s}\right)^{1-\sigma}+\left(c_{2}^{s s}\right)^{1-\sigma}-2\right)
$$

implies

$$
\left(c_{2}^{\sigma}\right) d W=\left(\frac{c_{2}}{c_{1}}\right)^{\sigma} d c_{1}+d c_{2}=\frac{F_{h}}{m} d c_{1}+d c_{2}
$$


Also,

$$
\begin{aligned}
d c_{1} & =\left(1-H^{s s}\right) d m-m d H^{s s} \\
d c_{2} & =\left(F_{h}+F_{H}\right) d H^{s s}
\end{aligned}
$$

Equations (10) - (12) combine to obtain the conditions in Proposition 2. 


\section{References}

[1] Armendáriz de Aghion, B. and J. Morduch (2005). The Economics of Microfinance. MIT Press: Cambridge, MA.

[2] Banerjee, Abhijit, Esther Duflo, Rachel Glennerster, and Cynthia Kinnan. (2009) "The Miracle of Microfinance? Evidence from a randomized evaluation." MIT working paper.

[3] Becchetti, Leonardo and Pierluigi Conzo (2010) "The controversial effects of microfinance on child schooling: A retrospective approach," ECINEQ Working Paper \#2010-173.

[4] Besley, T. and S. Coate (1995) "Group Lending, Repayment Incentives and Social Collateral," Journal of Development Economics, 46(1), pp. $1-18$.

[5] Coleman, Brett E. (1999) "The Impact of Group Lending in Northeast Thailand." Journal of Development Economics, volume 60, no 1.

[6] Daley-Harris, Sam (2009) "State of the Microcredit Summit Campaign Report 2009," Washington DC: Microcredit Summit Campaign.

[7] Field, E. and R. Pande. (2009) "Repayment Frequency and default in micro-finanace: Evidence from India," Journal of European Economics Association Papers and Proceedings, forthcoming. 
[8] Ghatak, Maitreesh and Guinnane, Timothy W. (1999) "The Economics of Lending with Joint Liability: Theory and practice," Journal of Development Economics, vol. 60(1), pages 195-228

[9] Giné, X. and D. Karlan (2006). "Group versus Individual Liability: Evidence from a Field Experiment in the Philippines." Yale University Economic Growth Center working paper 940.

[10] _____ and _____. (2009). "Group versus Individual Liability: Long Term Evidence from Philippine Microcredit Lending Groups," Yale University working paper.

[11] Islam, Asadul and Choe, Chongwoo (2009). "Child Labour and Schooling Responses to Access to Microcredit in Rural Bangladesh," MPRA Working Paper \#16842.

[12] Kaboski, J. and Townsend, R.(2005) "Policies and Impact: An Analysis of Village Microfinance Institutions." Journal of the European Economic Association, MIT Press, 3 (1): 1-50, 03.

[13] Karlan, D. and J. Zinman. (2009) "Expanding Credit Access: Using Randomized Supply Decisions To Estimate the Impacts," Review of Financial Studies, forthcoming.

[14] Maldonadoa, Jorge H. and Claudio González-Vega (2008) "Impact of Microfinance on Schooling: Evidence from Poor Rural Households in Bolivia," World Development, 36 (11): pp. 2440-2455. 
[15] Morduch, Jonathan. (1999) "The Microfinance Promise." Journal of Economic Literature Vol. XXXVII, pp. 1569-1614

[16] Pitt, M. and S. R. Khandker (1998). "The impact of Group-Based Credit Programs on Poor Households in Bangladesh: Does the Gender of Participants Matter?," Journal of Political Economy, 106.

[17] Psacharopoulos, George and Harry Anthony Patrinos (2004). "Returns to Investment in Education: A Further Update," Education Economics, 12(2), p. 111-134.

[18] Schroeder, Elizabeth (2010) "The Impact of Microcredit Borrowing on Household Consumption in Bangladesh." Mimeo, Georgetown University Economics Department.

[19] Stigler, George J. (1946) "The Economics of Minimum Wage Legislation," The American Economic Review, Vol. 36, No. 3, pp. 358-365.

[20] Stiglitz, Joseph E. (1990) "Peer Monitoring and Credit Markets," World Bank Economic Review, vol. 4, no 3, pp 351-366

[21] Varian, H. (1989) "Monitoring Agents With Other Agents," Journal of Institutional and Theoretical Economics 146, pp. 153-174.

[22] Wydick, Bruce (1999). "The effect of microenterprise lending on child schooling in Guatemala," Economic Development and Cultural Change; 47, 4; pp. 853-869. 